\title{
The American Board of Thoracic Surgery
}

\section{Notices}
7 he Part I (written) examination will be held at the Radisson Hotel O'Hare, Rosemont, Chicago, Illinois, on November 1 24, 2002. The closing date for registration is August 1, 2002. Those wishing to be considered for examination must request an application since it is not automatically sent.
To be admissible for the Part II (oral) examination, a candidate must have successfully completed the Part I (written) examination.
A candidate applying for admission to the certifying examina- tion must fulfill all the requirements of the Board in force at the time the application is received. Please address all communications to the American Board of Thoracic Surgery, One Rotary Center, Suite 803, Evanston, Illinois 60201 (telephone: 847-475-1520).

